\title{
SOME BIVARIATE DURRMEYER OPERATORS BASED ON $q$-INTEGERS
}

\section{DAN BăRbosu, CARmen Violeta Muraru AND ANA-Maria ACU}

Abstract. In the present paper we introduce a $q$-analogue of the bivariate Durrmeyer operators. A convergence theorem for these operators is established and the rate of convergence in terms of modulus of continuity is determined. Also, a Voronovskaja type theorem has been investigated for these operators.

Mathematics subject classification (2010): 41A10, 41A36.

Keywords and phrases: Positive linear operator, $q$-integers, $q$-Durrmeyer operator, $q$-beta function, modulus of continuity, $K$-functional.

\section{REFERENCES}

[1] T. ACAR, A. Aral, On Pointwise Convergence of q-Bernstein Operators and Their q-Derivatives, Numerical Functional Analysis and Optimization, 36 (3), 2015, 287-304.

[2] A. M. Acu, C. Muraru, V. Radu, F. Sofonea, Some approximation properties of a Durrmeyer variant of q-Bernstein-Schurer operators, Mathematical Methods in the Applied Sciences, DOI: 10.1002/mma.3949.

[3] A. M. ACU, Stancu-Schurer-Kantorovich operators based on q-integers, Applied Mathematics and Computation, 259 (2015), 896-907.

[4] O. AgRatini, On certain q-analogues of the Bernstein operators, Carpathian J. Math., 24 (3), 2008, 281-286.

[5] A. Aral, V. Gupta, R. P. Agarwal, Applications of $q$ Calculus in Operator Theory, Springer 2013, XII, $262 \mathrm{p}$.

[6] D. Barbosu, Some generalized bivariate Bernstein operators, Math. Notes, Miskolc, 1 (1), 2000, $3-10$.

[7] D. Barbosu, Polynomial approximation by means of Schurer-Stancu type operators, Ed. Univ. de Nord, Baia Mare, 2006, ISBN (10) 973-8138-81-5, (13) 978-973-8133-81-5.

[8] M. M. DeRriennic, Sur l'approximation des fonctions integrable on $[0,1]$ par des par des polynômes de Bernstein modifiés, J. Approx. Theory, 31, 1981, 325-343.

[9] P. L. ButZer, H. Berens, Semi-groups of operators and approximation, Springer, New York, 1967, $318 \mathrm{pp}$.

[10] M. M. DerRIEnNIC,, Modified Bernstein polynomials and Jacobi polynomials in q-calculus, Rend, Circ. Mat. Palermo, Serie II (Suppl. 76), 2005, 269-290.

[11] J. L. DurRmeYer, Une formule d'inversion de la transformée de Laplace: Application a la théorie des moments, These de 3-e cycle, Faculté des Sciences de l'Université de Paris, 1967.

[12] V. GuPTA, Some approximation properties of q-Durrmeyer operators, Appl. Math. Comput., 197, 2008, 172-178.

[13] V. Gupta AND Z. Finta, On certain q-Durrmeyer type operators, Appl. Math. Comput., 209, 2009, 415-420.

[14] A. LuPAS, A q-analogue of the Bernstein operator, University of Cluj-Napoca, Seminar on Numerical Analysis and Statistical Calculus, Preprint 9, 1987, 85-92.

[15] C. V. Muraru AND A. M. ACU, Some approximation properties of q-Durrmeyer-Schurer operators, Scient. Stud. res., Series Math. and Inf., 23 (1), 2013, 77-84.

[16] G. M. Phillips, Bernstein polynomials based on the q-integers, Ann. Numer. Math., 4, 1997, 511518. 
[17] G. M. PhILliPS, Interpolation and Approximation by Polynomials, CMS Books in Math., 14, Springer, 2003.

[18] O. Shisha, P. Mond, The degree of convergence of linear positive operators, Proc. Nat. Acad. Sci. USA 60, 1968, 1196-1200.

[19] D. F. Sofonea, Some new properties in q-calculus, General Mathematics, 16 (1), 2008, 47-54.

[20] D. F. SofoneA, On a sequence of linear and positive operators, Result. Math., 53, 2009, 435-444.

[21] J. Thомав, Beitrage zur Theorie durch die Heinische Reihe, J. Reine Angew. Math., 70, 1869, 258281.

[22] V. J. VOLKOV, On the convergence of linear positive operators in the space of continuous functions of two variables (Russian), Dokl. akad. Nauk. SSSR (N. S), 115, 1957, 17-19. 